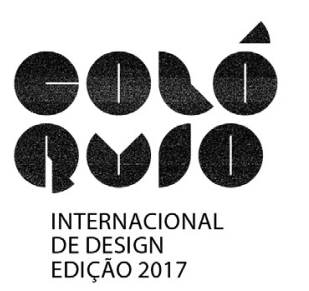

\title{
Análise Bibliométrica dos Termos Design e Criatividade no Portal de Periódicos Capes
}

\author{
Aline Freitas da Silva Xavier; \\ Samantha Cidaley de Oliveira Moreira;
}

resumo:

Este artigo apresenta a análise bibliométrica dos termos design e criatividade. Esta ferramenta metodológica, denominada análise bibliométrica é um método flexível para avaliar a tipologia, a quantidade e a qualidade das fontes de informações citadas em pesquisas. Os indicadores científicos dessa produção são o produto dessa análise bibliométrica.

Há diferentes definições para a palavra design, mas vários de seus autores concordam com a sua transdisciplinaridade. Isso se dá pois o design transita em várias áreas, dentre elas a criatividade. A relação do design com a criatividade é um fenômeno cada vez mais relevante e importante a se considerar. Nesta pesquisa essa relação se dá através da análise bibliométrica das palavras-chave "design" e "criatividade" em artigos publicados no período de 2000 a 2016, observando a coexistência do design com distintas áreas do conhecimento. Eis que o objetivo desta pesquisa, foi identificar o volume de publicações científicas, disponíveis no portal de periódicos da Capes, que relacionam design e criatividade, apresentando um panorama sobre o número de investigações disponíveis sobre os termos. Diante deste contexto, a questão norteadora desta pesquisa bibliométrica é: Qual o atual estágio do uso dos termos design e criatividade no portal de periódicos da Capes?

Neste levantamento inicial a pesquisa foi feita usando apenas os termos em português, o que limita muito os resultados encontrados, uma vez que as bases de dados tem a maioria de seus acervos de publicações internacionais. Os resultados são apresentados através de imagens e gráficos que possibilitam apresentar, como resultado relevante, as principais bases de dados e periódicos onde ocorreram publicações com uso dos termos design e criatividade.

palavras-chave:

Bibliometria; Design; Criatividade 


\section{Introdução}

No cenário mundial atual tudo muda o tempo todo. As pessoas querem novos produtos e serviços a todo momento e o nível de exigência vem aumentado. Nesse contexto, o designer exerce um papel fundamental e a criatividade tende ser uma de suas competências mais fortes. Isso porque o designer precisa se antecipar aos problemas, buscando aplicar sua criatividade para proposição de variadas soluções, em diferentes projetos, a fim de auxiliar na definição de estratégias, na criação de oportunidades e na liderança de projetos multidisciplinares. Afinal, cada vez mais a criatividade e o design ganham terreno tanto no mundo político, como empresarial e educacional (Weiner, 2010, p.13).

Diante do contexto explicitado, a questão norteadora desta pesquisa bibliométrica é: Qual o atual estágio do uso dos termos design e criatividade no portal de periódicos da Capes?

Para este levantamento definiu-se por uma busca ampla no portal de periódicos da Capes, ao invés de definir uma de suas bases de dados. A busca limitou-se ao período de 2000 à 2016, e apresenta seu crescimento ao longo dos anos.

Esta pesquisa se mostra relevante para a comunidade acadêmica em design, ao apresentar um panorama sobre o número de investigações disponíveis, no citado portal, na área em específico, e o relacionamento as diversas áreas do conhecimento. Além disso, as informações aqui dispostas poderão orientar outros pesquisadores e facilitar a busca por interconexões com sua área de atuação.

\section{Design}

Conceituar o design implica entender sua natureza, conhecer os diversos campos em que pode atuar e os métodos empregados pela atividades (MOZOTA, 2011).

Em inglês, a palavra design mantém o duplo significado. É usada com muita frequência, podendo significar: plano, projeto, intenção, esquema e processo ou esboço, modelo, motivo, decoração, composição visual e estilo (Silva, 2014, p. 37).

Segundo Bomfim (1995, p. 09),

as definições de design variam de acordo com os contextos sócio-econômico-políticos e temporais em que foram criadas. São, portanto definições formais, ou seja, convenções que têm validade limitada a um determinado espaço histórico e geográfico, ainda que muitas vezes fossem usadas como se fossem universais.

Design é um método com a qual se pode contar para melhorar o padrão de qualidade dos objetos, assim como facilitar a percepção, compreensão, aquisição e relacionamento das pessoas com os objetos. Essas qualidades e facilidades são planejadas, concebidas, específicas e determinadas, aliadas à tecnologia e aos processos de produção (GOMES FILHO, 2003).

$\mathrm{O}$ design aliado a criatividade pode reunir e integrar diversos fatores que possibilitem a inovação de produtos, processos e serviços.

\section{Criatividade}

Substantivo feminino que segundo o dicionário Houais, é a "qualidade ou características de quem [...] é criativo". 1. qualidade ou característica de quem ou do que é criativo. 2. inventividade, inteligência, talento nato ou adquiridos, para criar, inventar, inovar, quer no campo artístico quer no científico, esportivo, etc.

A definição de criatividade é objeto de estudo de diversos pesquisadores e estudiosos, havendo diversas linhas de entendimento que justificam a dimensão de seu conceito e a dificuldade de um consenso. Em termos mais gerais, a criatividade é a capacidade que um indivíduo tem em criar algo, seja inovando, com uma concepção inédita, ou ainda aperfeiçoando e dando nova identidade a um produto ou conteúdo já existente ${ }^{1}$.

\footnotetext{
${ }^{1}$ http://www2.faac.unesp.br/pesquisa/lecotec/mediawiki/index.php/Criatividade
} 
A criatividade é uma das etapas do processo de design e é obtida através de associação entre exercícios, ferramentas e o contato com nosso eu interior. Parafraseando Albert Eisten, criatividade é capacidade da mente se divertir!

\section{Procedimentos Metodológicos}

Para este estudo utilizou-se a técnica de pesquisa denominada Bibliometria, esta técnica é definida como uma ferramenta estatística para avaliar e medir por meio de mapeamento e geração de indicadores de tratamento e gestão da informação e do conhecimento (HAYASHY e LETA, 2013).

A análise bibliométrica é um método flexível para avaliar a tipologia, a quantidade e a qualidade das fontes de informações citadas em pesquisas. Os indicadores científicos dessa produção são o produto dessa análise bibliométrica. Nesse sentido, a bibliometria demonstrou ser uma ferramenta eficaz que permite obter um espectro abrangente das produções científicas acerca do design e criatividade no portal de periódicos da Capes.

O objetivo deste estudo é identificar o volume de pesquisas científicas que relacionam design e criatividade, em artigos do portal de periódicos da Capes, entre os anos de 2000 e 2016. Por se tratar de uma análise inicial, optou-se por fazer uma busca geral nas bases do portal (figura 01), através do seu mecanismo de busca e não em um banco de dados específicos e também optou-se por utilizar neste primeiro momento os termos em português.

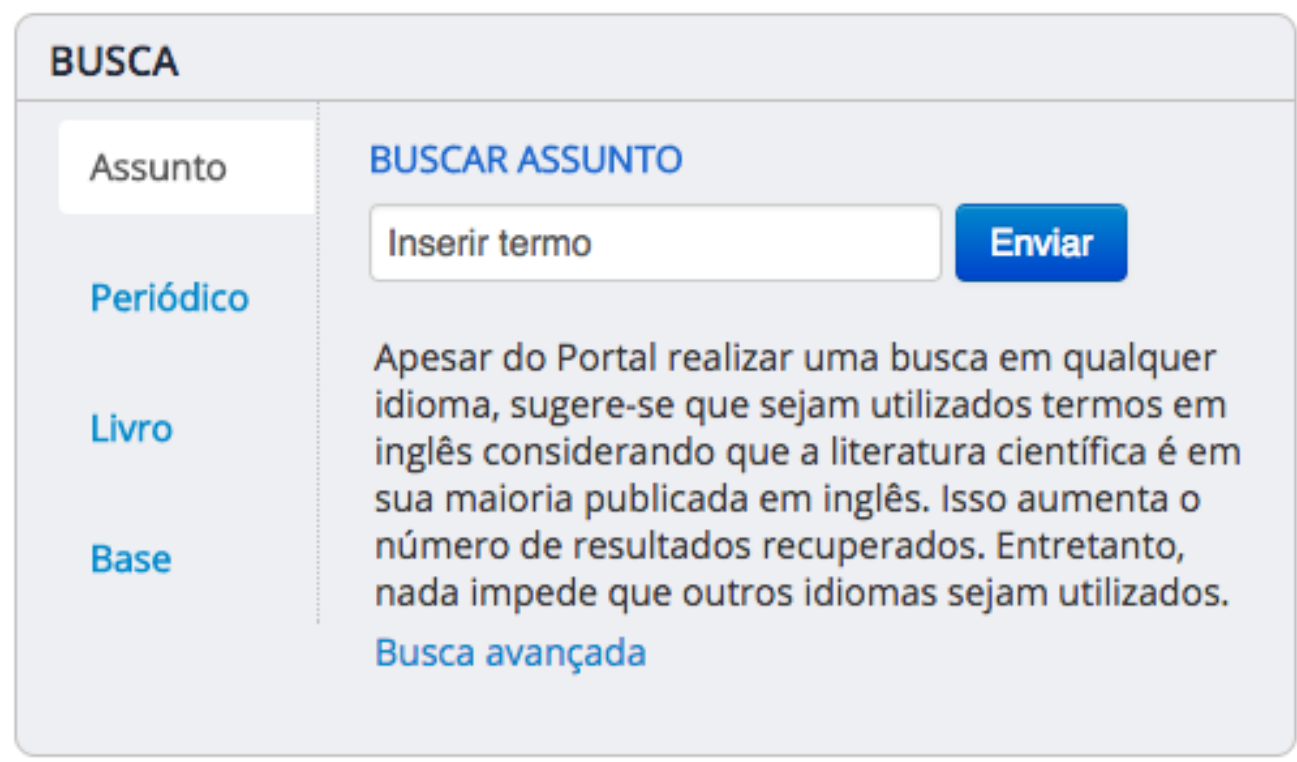

Figura 01: Espaço de busca do portal de periódicos Capes

Fonte: www.periodicos.capes.gov.br

No desenvolvimento da pesquisa as etapas que nortearam a coleta de dados foram previamente definidas, assim como foram estabelecidos critérios que orientassem as pesquisas no banco de dados, facilitando o alcance do objetivo proposto. As etapas e critérios de pesquisa, o que constitui o método de pesquisa para desenvolvimento dessa pesquisa, estão dispostos no quadro seguir: 


\begin{tabular}{|l|l|}
\hline \multicolumn{1}{|c|}{$\begin{array}{c}\text { Etapas da Análise } \\
\text { Bibliométrica }\end{array}$} & \multicolumn{1}{c|}{ Descrição } \\
\hline 1 - Definir a Pergunta & $\begin{array}{l}\text { Qual o atual estágio do uso dos termos design e criatividade } \\
\text { no portal de periódicos da Capes? }\end{array}$ \\
\hline $\begin{array}{l}\text { 2 - Identificar a base de dados a ser } \\
\text { consultada, definir palavras-chave } \\
\text { e estratégias de busca }\end{array}$ & $\begin{array}{l}\text { Para a coleta dos estudos, optou-se por realizar as buscas no } \\
\text { portal de periódicos Capes, na qual a busca foi conduzida } \\
\text { através das palavras-chave: Design e Criatividade (em } \\
\text { português). }\end{array}$ \\
\hline $\begin{array}{l}\text { 3 - Estabelecer critérios de } \\
\text { inclusão/exclusão de artigos }\end{array}$ & $\begin{array}{l}\text { Foi definido o período de 2000 à 2016 para o período de } \\
\text { publicação dos artigos pesquisados. Não houve restrição de } \\
\text { áreas de publicação para a pesquisa. }\end{array}$ \\
\hline $\begin{array}{l}\text { 4 - Busca em base de dados } \\
\text { escolhidas e com base em } \\
\text { estratégias definidas }\end{array}$ & $\begin{array}{l}\text { Foram selecionados artigos que tinham em seu título as } \\
\text { palavras-chave definidas para a pesquisa. }\end{array}$ \\
\hline $\begin{array}{l}5 \text { - Comparar as buscas dos } \\
\text { examinadores e definir seleção de } \\
\text { artigos }\end{array}$ & $\begin{array}{l}\text { As buscas apresentaram 32 artigos, porém ao limitar aos } \\
\text { artigos revisados por pares o número cai para 14. }\end{array}$ \\
\hline $\begin{array}{l}\text { 6 - Aplicar os critérios na seleção } \\
\text { dos artigos e justificar possíveis } \\
\text { exclusões }\end{array}$ & $\begin{array}{l}\text { Vários foram os critérios utilizados, todos estão detalhados no } \\
\text { tópico resultados e discussões. }\end{array}$ \\
\hline $\begin{array}{l}7 \text { - Analisar criticamente e avaliar } \\
\text { todos os estudos incluídos na } \\
\text { revisão }\end{array}$ & $\begin{array}{l}\text { As informações dos trabalhos foram organizadas e tabeladas } \\
\text { de maneira que fosse possível desenvolver comparações e } \\
\text { análises. }\end{array}$ \\
\hline $\begin{array}{l}\text { 8 - Quantificar e Qualificar os } \\
\text { dados }\end{array}$ & $\begin{array}{l}\text { Os dados foram quantificados a partir do suporte de planilhas } \\
\text { e gráficos produzidos pela autora e através de informações do } \\
\text { portal de periódicos Capes. }\end{array}$ \\
\hline $\begin{array}{l}\text { 9 - Apresentar uma conclusão, } \\
\text { informando a evidência sobre os } \\
\text { efeitos da intervenção }\end{array}$ & $\begin{array}{l}\text { A partir da análise das informações contidas nos 14 artigos } \\
\text { foi possível mapear as questões apresentadas neste artigo. }\end{array}$ \\
\hline
\end{tabular}

Quadro 01: Etapas para a análise bibliométrica

Fonte: Adaptado de Brereton et al (2007) apud Lorenzini, Libânio e Amaral (2014)

\section{Resultados e Discussões}

A pesquisa no portal de periódicos da Capes teve como filtro, no primeiro momento, apenas o período de publicação, que foi de 2000 à 2016 (figura 02), e no universo geral da pesquisa onde o termo pode ser encontrado, o que nos permitiu ter uma visão ampliada das publicações disponíveis nas várias áreas e periódicos do portal. 


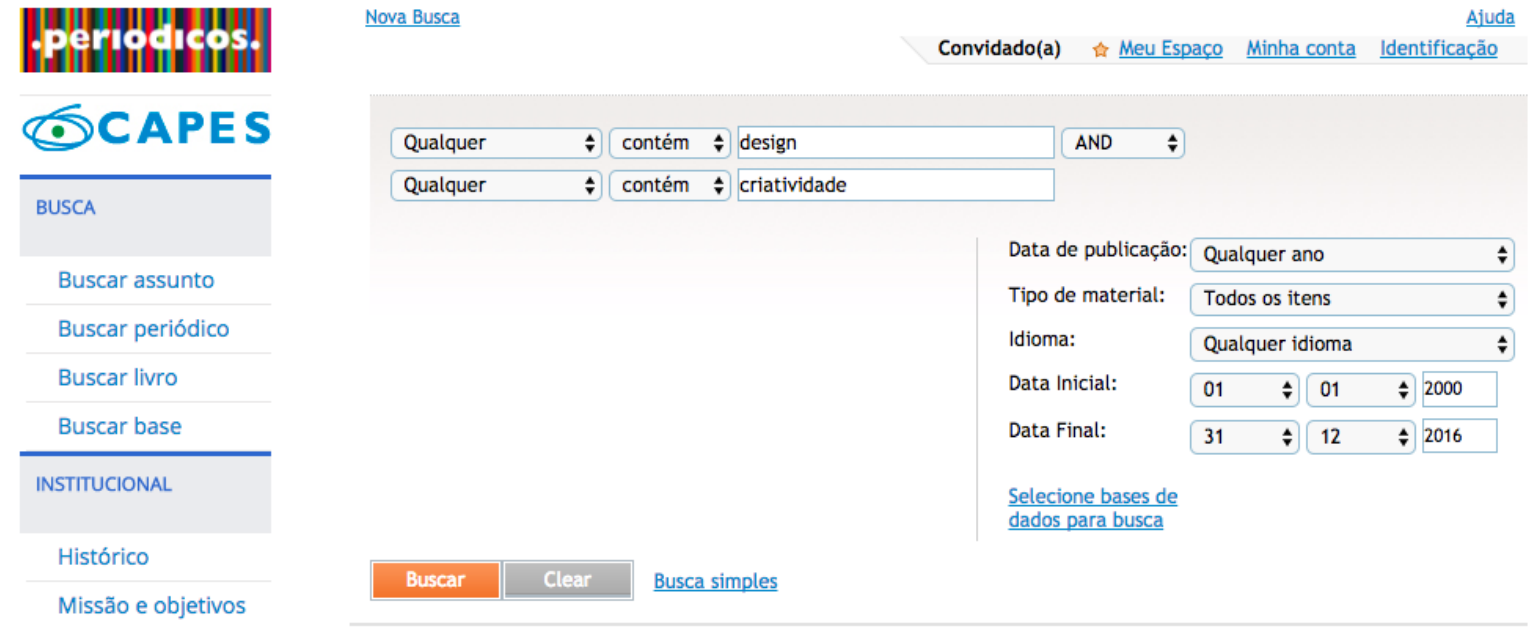

Figura 02: Espaço de busca avançada do portal de periódicos Capes

Fonte: www.periodicos.capes.gov.br

Nessa busca foram encontrados 347 itens (figura 03), sendo que, destes 240 foram revisados por pares.

\begin{tabular}{|c|c|c|c|}
\hline - Personalize your & $\begin{array}{l}\text { Resultados de } 1 \text { - } 10 \text { para } 347 \\
\text { para Portal de Periodicos }\end{array}$ & $\begin{array}{l}\text { Ordenado por: } \\
\text { Relevância } \vee\end{array}$ & $1 \underline{2} \underline{3} \underline{4} \underline{5} \Rightarrow$ \\
\hline Edit & Mostrar somente Periódicos rev & por pares $(240)$ & \\
\hline
\end{tabular}

Figura 03: Resultados das buscas iniciais no portal de periódicos Capes

Fonte: www.periodicos.capes.gov.br

Considerando que, a revisão por pares se constitui como valor, uma vez que pressupõe maior credibilidade do conteúdo discutido nas publicações, optou-se por utilizar este filtro. Do disposto, o número de artigos a serem analisados reduziu em cerca de $30 \%$, caindo para 240 itens correspondentes à pesquisa. A figura 04 apresenta as áreas dos periódicos e os números dos artigos publicados: 


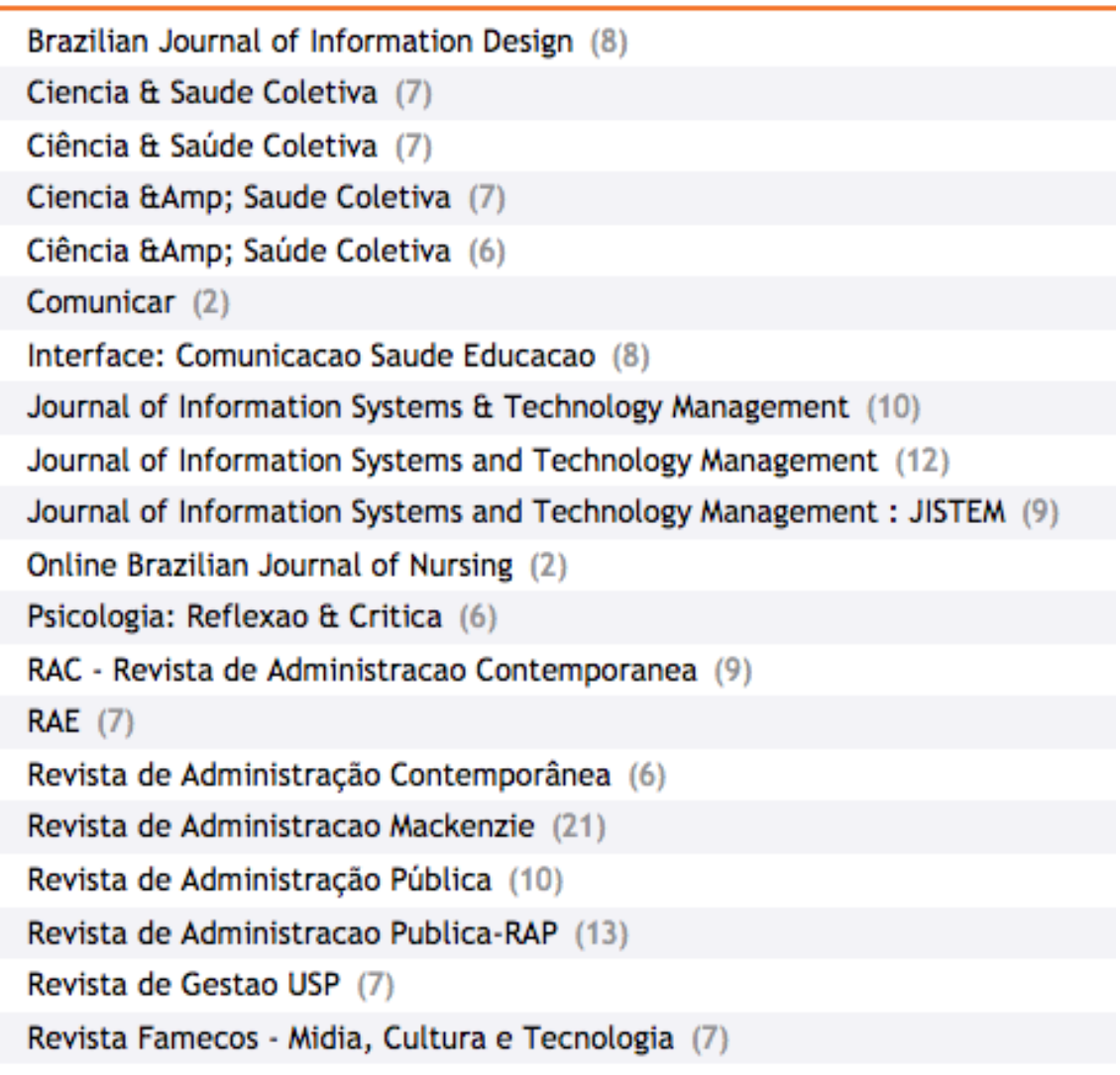

Figura 04: Lista de periódicos

Fonte: www.periodicos.capes.gov.br

Analisando os dados dispostos na figura 04, e agrupando os periódicos em áreas correlatas, é possível compreender que o maior número de publicações com o uso dos termos design e criatividade estão nos periódicos de administração (66), seguido por informação e tecnologia (31) e, na sequencia, ciência e saúde (27). Dos periódicos listados, apenas um é específico de design e nele foram encontrados apenas 8 publicações, com os termos tratados nesse artigo.

As publicações citadas acima foram encontradas em 20 das bases de dados, disponíveis no Portal de Periódicos da Capes, conforme listado na figura 05. 


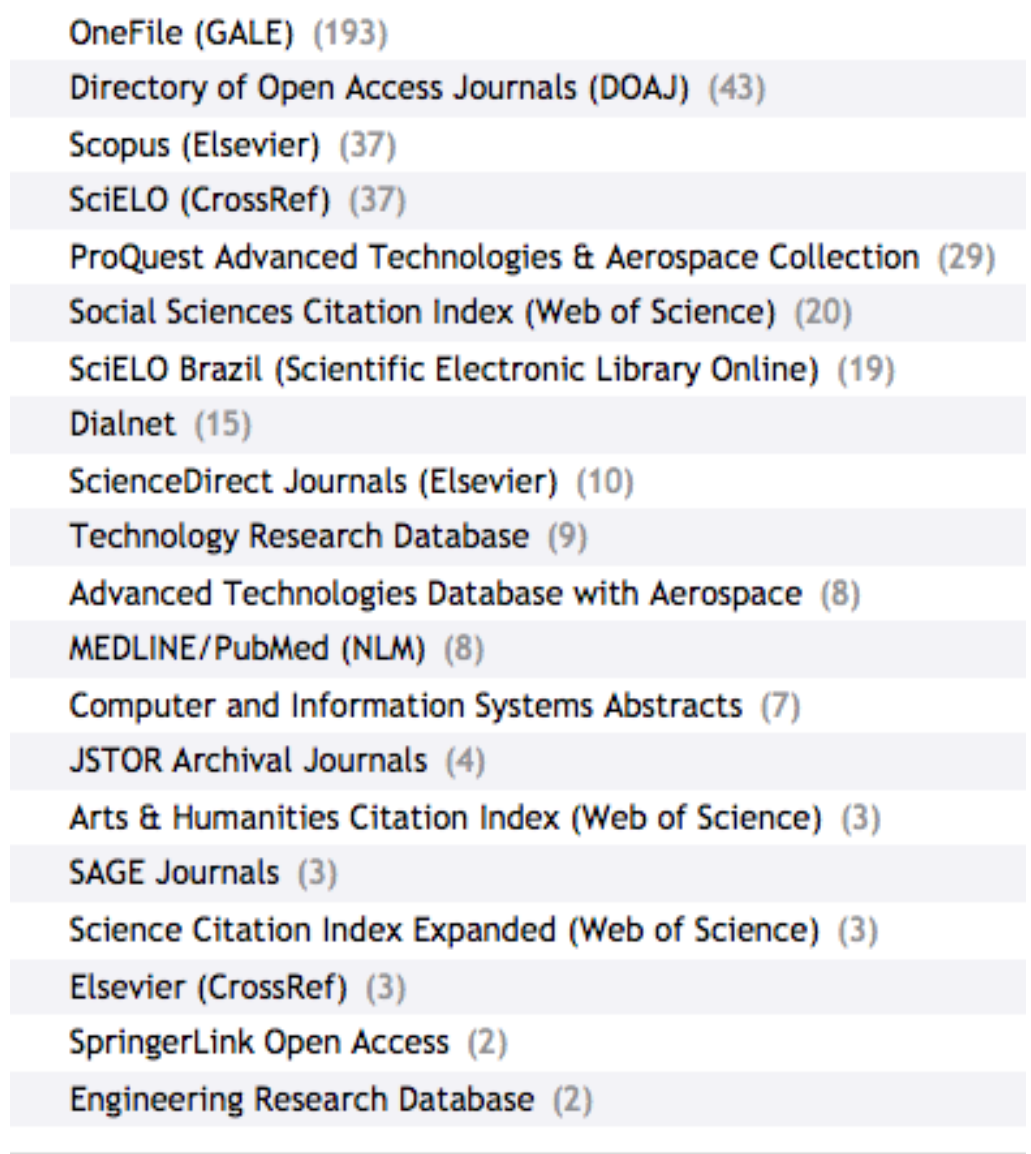

Figura 05: Lista de bases de dados

Fonte: www.periodicos.capes.gov.br

Conhecendo o cenário da pesquisa, foi possível definir quatro bases de dados do Portal de Periódicos da Capes para avançar nas pesquisas futuras sobre design e criatividade. São elas, em números:

- OneFile (GALE): 193 artigos

- Directory of Open Access Journals (DOAJ): $\mathbf{4 3}$ artigos

- Scorpus (Elsevier): $\mathbf{3 7}$ artigos

- Scielo (CrossRef): $\mathbf{3 7}$ artigos

Listar esse quatro repositórios, não implica dizer que são os melhores, ou que apenas neles, seria interessante aprofundar a pesquisa, porém estão neles os maiores números de publicações encontradas nesse estudo.

Retomando a questão do marco temporal das publicações no portal, ressalta-se que o período definido, inicialmente, para limitar a pesquisa foi de 2000 à 2016, porém só foram encontradas publicações a partir de 2001 .

Analisando os anos de publicações é possível notar que 2014 foi o ano com o maior número de publicações, 41 artigos, seguido de 2015, com 39 e 2013, com 34, como se pode ver no gráfico 01. 


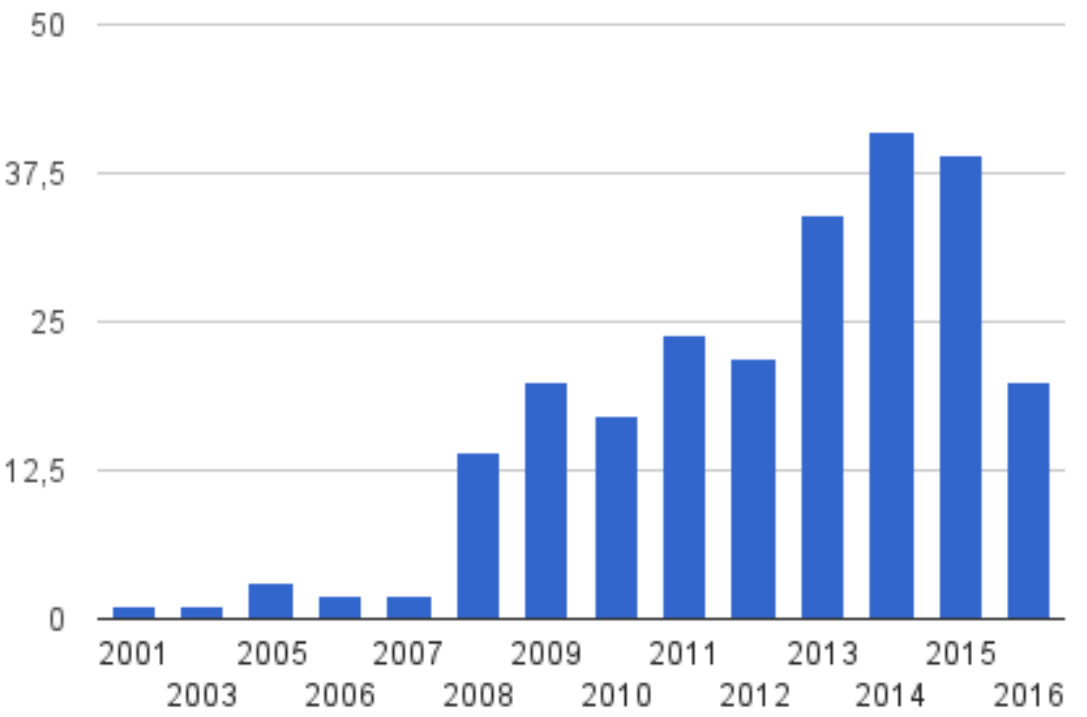

Gráfico 01: $\mathrm{N}^{\mathrm{o}}$ de publicações por ano Fonte: arquivos da autora

Após o levantamento do número de publicações por ano optou-se por incluir mais um filtro e fazer a busca por materiais que contenham, em seu título, tanto a palavra design quanto criatividade (figura 06).

Nova Busca

Aline Freitas da Silva Xavier 亩 Meu Espaço Minha conta Sair

\begin{tabular}{lllll}
\hline no título & contém & design & AND \\
\hline no título & $>$ contém & - criatividade
\end{tabular}

$\begin{array}{llll}\text { Data de publicação: } & \text { Qualquer ano } \\ \text { Tipo de material: } & \text { Todos os itens } \\ \text { Idioma: } & \text { Qualquer idioma } & \\ \text { Data Inicial: } & 01 & & \\ \text { Data Final: } & 31 & \end{array}$

Selecione bases de

dados para busca

Figura 06: Busca por título

Fonte:www.periodicos.capes.gov.br

Com a aplicação deste filtro apenas um resultado (figura 07) foi encontrado. O arquivo tem como título "A criatividade no ensino do design" ${ }^{2}$ cuja autoria é de Rui Weiner e a publicação é de 2010. O documento é uma dissertação de mestrado em design gráfico e projetos editoriais da Faculdade de Belas Artes da Universidade de Porto, em Portugal. 


\section{Personalize your results \\ $\underline{\text { Edit }}$ \\ Expandir meus resultados \\ Expandir meus resultados}

\section{Resultados para Portal de Ordenado por: Periodicos \\ Data - mais recente $\checkmark$}

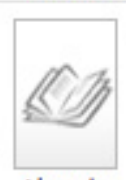

thesis

\section{A Criatividade no ensino do Design}

Rui Weiner 2010

Repositório Cientfico de Acesso Aberto de Portugal

- Texto completo disponivel

\begin{tabular}{ll} 
Exibir online & Detalhes \\
1 Resultados para Portal de & $\begin{array}{l}\text { Ordenado por: } \\
\text { Data-mais recente }\end{array}$ \\
\hline
\end{tabular}

Figura 07: Resultado da busca por título

Fonte: www.periodicos.capes.gov.br

De acordo com o autor, aquela pesquisa foi desenvolvida na perspectiva da construção de uma nova disciplina no ensino do design, com o propósito de apoiar o desenvolvimento do pensamento criativo do estudante de designer (Weiner, 2010, p. 07). Outro filtro aplicado foi a busca por assunto, como demonstrado na figura 08 .

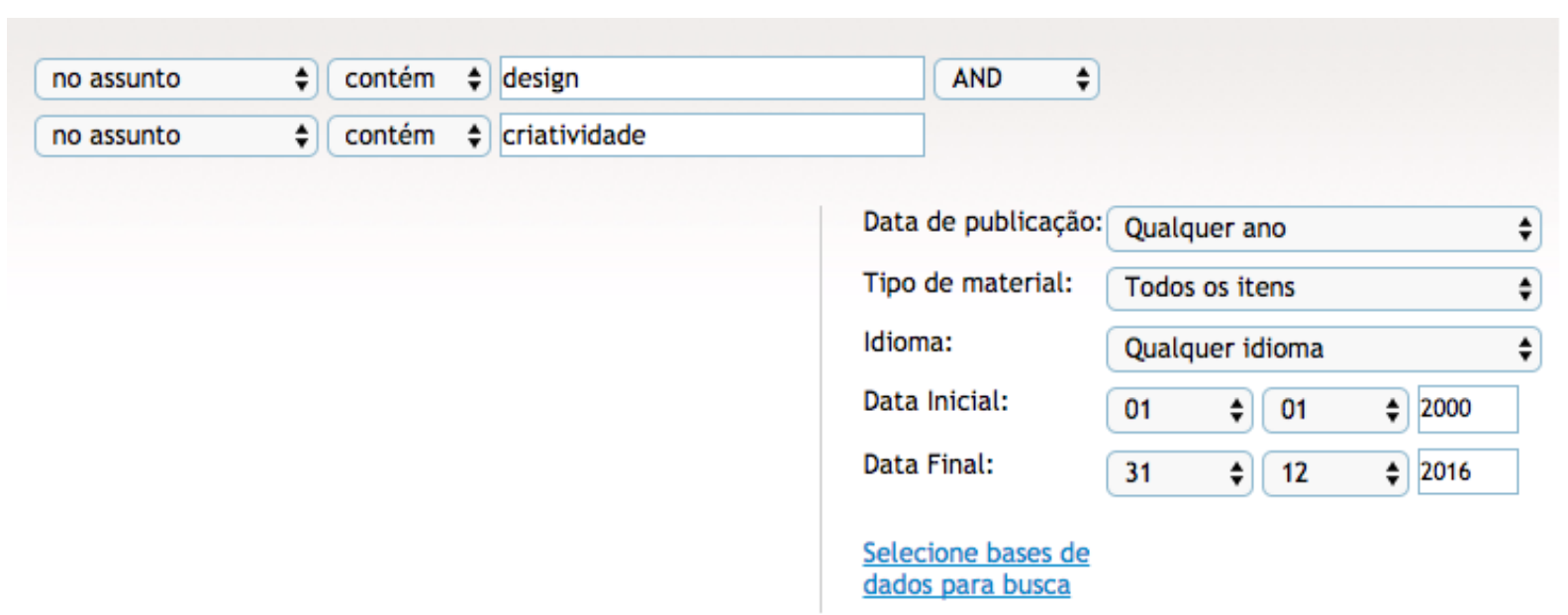

\section{\begin{tabular}{l|l|l} 
Buscar & Clear & Busca simples
\end{tabular}}

Figura 08: Busca por assunto

Fonte: www.periodicos.capes.gov.br

Novamente apenas um artigo foi encontrado. O arquivo tem como título "Industrias Creativas de Diseño de Indumentaria de Autor. Diagnóstico y desafios a 10 años del surgimiento del fenómeno en Argentina ", de autoría de Laureano Mon, publicado em 2012, em periódico argentino. O documento é um artigo de 16 páginas, publicado no Cuaderno do Centro de Estudios en Diseño y Comunicación, número 42. O artigo apresenta um diagnóstico produtivo e cultural da indústria e do design de moda após 10 anos do surgimento dos direitos de autor, a fim de permitir medir o impacto real disto no setor, identificando os principais desafios para alcançar a longo prazo a sustentabilidade e o desenvolvimento econômico e social.

Vale ressaltar que os dois arquivos supra citados, na busca por título - "A criatividade no ensino do design" e por assunto - "A criatividade no ensino do design, 2010" e "Industrias Creativas de Diseño de Indumentaria de Autor. Diagnóstico y desafios a 10 años del surgimiento del fenómeno

\footnotetext{
${ }^{3}$ http://fido.palermo.edu/servicios_dyc/publicacionesdc/archivos/378_libro.pdf
} 
en Argentina, 2012", não foram publicados nos anos e nos periódicos com maior número de publicação.

Importante a reflexão que, se no primeiro momento, tivéssemos limitado a busca por título, assunto ou mesmo mesmo área de conhecimento, essa pesquisa ficaria muito restrita e não apresentaria resultados relevantes. A pesquisa por período de publicação nos possibilitou conhecer e apresentar, como resultado relevante, as principais bases de dados e periódicos onde ocorreram publicações com uso dos termos design e criatividade.

\section{Considerações Finais}

Este artigo apresentou uma análise bibliométrica acerca dos termos design e criatividade no portal de periódicos da Capes. Considera-se este como um levantamento inicial e amplo, uma vez que não se limitou a uma base de dados específica. Vale lembrar que o objetivo dessa pesquisa foi conhecer o atual estágio do uso dos termos design e criatividade no portal de periódicos da Capes. Assim, a analise dos motivos que determinaram o volume de publicações com os termos design e criatividade, ano a ano, pode ser explorado em pesquisa futura.

Sobre as análises realizadas, no Portal de Periódicos da Capes, entendemos que os pesquisadores, ao iniciar o trabalho de levantamento de dados, terá embasamento para definir melhor o caminho que precisará seguir para delimitar e aprofundar as suas pesquisas, sistematizando os mecanismos de busca e diversificando os filtros, escolhendo a base de dados que aprofundará a pesquisa, etc.

Optou-se por neste momento pesquisar apenas os termos em português o que limita muito os resultados encontrados, uma vez que as bases de dados tem a maioria de seus acervos de publicações internacionais. Essa pode ser mais uma sugestão de pesquisa futura e uma ampliação desta, seria importante antes mesmo de um aprofundamento e definições mais restritas como as sugeridas anteriormente.

Concluímos que nem sempre os números resultantes do levantamento bibliográfico é o único norteador que o pesquisador deve considerar, pois tudo depende do objetivo que se pretende atingir com este tipo de levantamento.

\section{Bibliometric Analysis of Terms Design and Creativity in the Portal of Capes Journals}

\section{Abstract:}

This article presents the bibliometric analysis of the terms design and creativity. This methodological tool, called bibliometric analysis, is a flexible method to evaluate the typology, quantity and quality of the sources of information cited in research. The scientific indicators of this production are the product of this bibliometric analysis.

There are different definitions for the word design, but several of its authors agree with its transdisciplinarity. This is because the design transits in several areas, among them creativity. The relationship between design and creativity is an increasingly important and important phenomenon to consider. In this research, this relationship occurs through the bibliometric analysis of the keywords "design" and "creativity" in articles published in the period from 2000 to 2016, observing the coexistence of design with different areas of knowledge. The objective of this research was to identify the volume of scientific publications available in Capes' journals portal, which relate design and creativity, presenting an overview of the number of investigations available on the terms. Given this context, the guiding question of this bibliometric research is: What is the current stage of the use of the terms design and creativity in the portal of journals of Capes? 
In this initial survey the research was done using only the Portuguese terms, which greatly limits the results found, since the databases have the majority of their collections of international publications. The results are presented through images and graphs that make it possible to present, as a relevant result, the main databases and periodicals where publications have occurred using the terms design and creativity.

key words:

Bibliometry; Design; Creativity

\section{Referências bibliográficas}

BOMFIM, Gustavo A. Metodologia para desenvolvimento de projetos. Campina Grande: UFPB, 1995.

CARDOSO, Rafael. Uma Introdução à história do design. São Paulo: Edgar Blücher, 2008.

CRIATIVIDADE. Disponível em:

http://www2.faac.unesp.br/pesquisa/lecotec/mediawiki/index.php/Criatividade . Acesso em: 03 de janeiro de 2017.

GOMES FILHO, João. Ergonomia do objeto: sistema prático de leitura ergonômica. São Paulo: Escrituras Editora, 2003.

HAYASHY, M.C.P.I; LETA, J. Bibliometria e cientometria: reflexões teóricas e interfaces. São Carlos: Pedro \& João Editores, 2013.

LORENZINI, G. C; LIBÂNIO, C. S; AMARAL, F. G. Aspectos da gestão de design abordados em artigos: uma análise bibliométrica. IN 6 P\&D Design, 2014.

MOZOTA, Brigitte Borja de; KLÖPSCH, Cássia; COSTA, Felipe C. Xavier da. Gestão de Design: usando o design para construir valor de marca e inovação corporativa. Porto Alegre: Bookman, 2011. $344 \mathrm{p}$.

SILVA, Aline Freitas da. 0 estudo da dimensão social do design sustentável como estratégia para o trabalho do designer na EaD. 2014. Dissertação (Mestrado em Design) Universidade do Estado de Minas Gerais, Belo Horizonte, 2014.

VIANA, Sebastião Fernando. 0 Espiral da Criatividade. Disponível em: http://criatividadeeinovacao.com.br/ebook/A_espiral_criativa.pdf . Acesso em: 23 de dezembro de 2016.

WEINER, Rui S. de Bastos. A Criatividade no ensino do design. 2010. Dissertação (Mestrado em Design Gráfico e Projetos Editoriais) Universidade do Porto, Porto, 2010. 